Supporting information

\title{
Ratiometric Fluorescent Biosensing of Hydrogen Peroxide and Hydroxyl Radical in Living Cells with Lysozyme-Silver Nanoclusters: Lysozyme as Stabilizing Ligand and Fluorescence Signal Unit
}

\author{
Fang Liu, ${ }^{\dagger}$ Tao Bing ${ }^{\ddagger}$, Dihua Shangguan ${ }^{\ddagger}$, Meiping Zhao ${ }^{\S}$ and Na Shao ${ }^{*}{ }^{\dagger}$ \\ ${ }^{\dagger}$ College of Chemistry, Beijing Normal University, Beijing 100875, P. R. China \\ ${ }^{\ddagger}$ Beijing National Laboratory for Molecular Sciences, Key Laboratory of Analytical \\ Chemistry for Living Biosystems, Institute of Chemistry, Chinese Academy of \\ Sciences, Beijing 100190, P. R. China \\ ${ }^{\S}$ Beijing National Laboratory for Molecular Sciences, College of Chemistry and \\ Molecular Engineering, Peking University, Beijing 100871, P. R. China \\ *Corresponding author: E-mail: shaona@ bnu.edu.cn. Fax: +86-10-58802146.
}

Content: 
1. UV-visible Absorption Spectra of dLys-AgNCs and Its Response to Fenton Reagents

Figure S1. UV-visible absorption spectra of dLys-AgNCs $\quad$.......................... S-3

Figure S2 Effect of $\mathrm{Fe}^{3+}$ on fluorescence characteristics of dLys-AgNCs $\quad . . . . . \mathrm{S}-3$

Figure S3. Effect of NaF and thiourea on fluorescence characteristics of

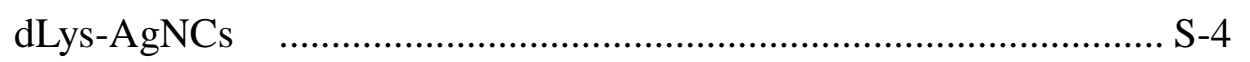

Figure S4. Effect of Fenton reagents on the circular dichroism (CD) spectra of

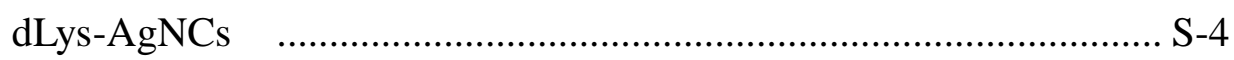

\section{Ratiometric Fluorescent Detection of $\mathrm{H}_{2} \mathrm{O}_{2}$}

Figure S5. Effect of probe concentration on the sensing of dLys-AgNCs toward $\mathrm{H}_{2} \mathrm{O}_{2}$

Figure S6. Effect of $\mathrm{Fe}^{2+}$ concentration on the sensing of dLys-AgNCs toward $\mathrm{H}_{2} \mathrm{O}_{2}$ S-5

Figure S7. Time-dependent sensing of dLys-AgNCs toward $\mathrm{H}_{2} \mathrm{O}_{2}$.................. S-6

Figure S8. Effect of $\mathrm{pH}$ on the sensing of dLys-AgNCs toward $\mathrm{H}_{2} \mathrm{O}_{2} \quad$........... S-6

\section{Ratiometric Fluorescent Detection of $\mathrm{H}_{2} \mathrm{O}_{2}$-generated Oxidase Systems}

Figure S9. Effect of glucose and GOx on fluorescence characteristics of dLys-AgNCs

Figure S10. Effect of GOx concentration on the sensing of dLys-AgNCs toward glucose

Figure S11. Time-dependent sensing of dLys-AgNCs toward glucose S-8

Figure S12. Effect of $\mathrm{ACh}, \mathrm{AChE}$ and $\mathrm{ChOx}$ on fluorescence characteristics of dLys-AgNCs S-8

Figure S13. Effect of AChE/ChOx concentrations on the sensing of dLys-AgNCs toward ACh S-9

Figure S14. Time-dependent sensing of dLys-AgNCs toward ACh S-9

\section{Interference Study}

Figure S15. Ratiometric fluorescent responses of dLys-AgNCs to metal ions . S-10 


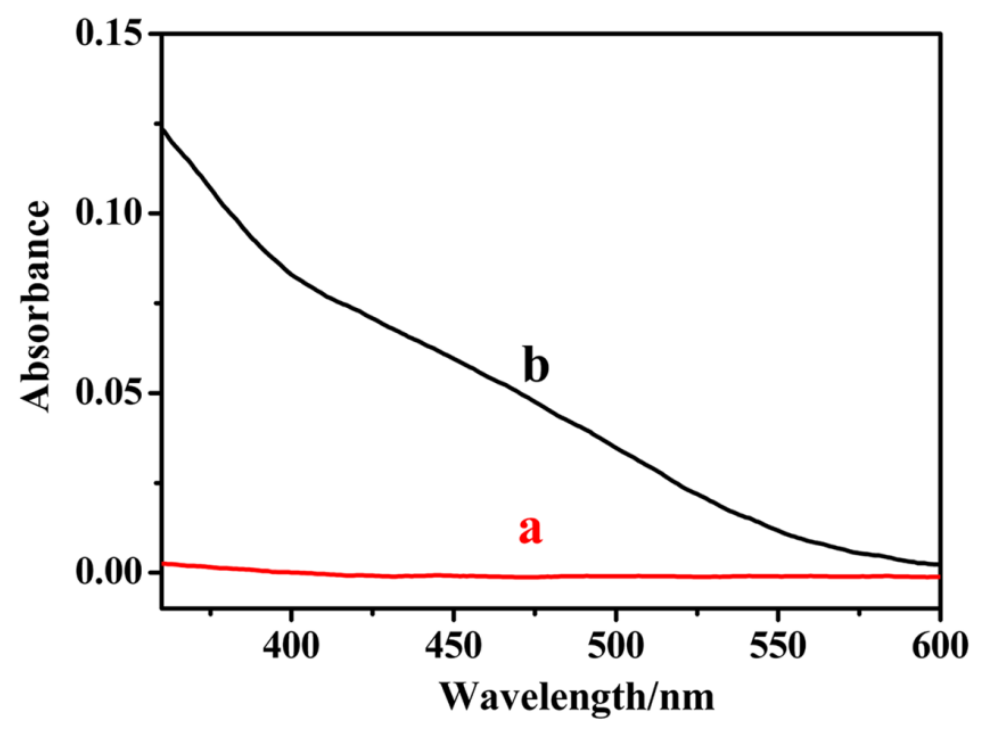

Figure S1. The UV-visible absorption spectra of (a) denatured lyspzyme and (b) dLys-AgNCs.

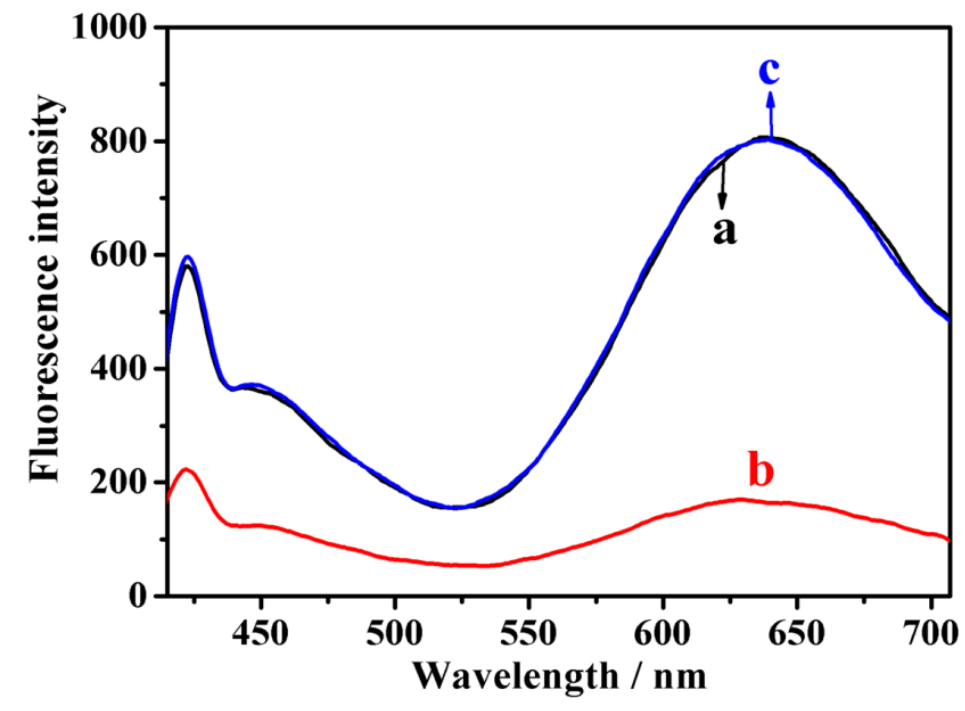

Figure S2. Fluorescence spectra of (a) dLys-AgNCs, (b) dLys-AgNCs $+0.5 \mathrm{mM} \mathrm{Fe}$ and (c) dLys-AgNCs $+0.5 \mathrm{mM} \mathrm{Fe}^{3+}+15 \mathrm{mM} \mathrm{NaF}$. 


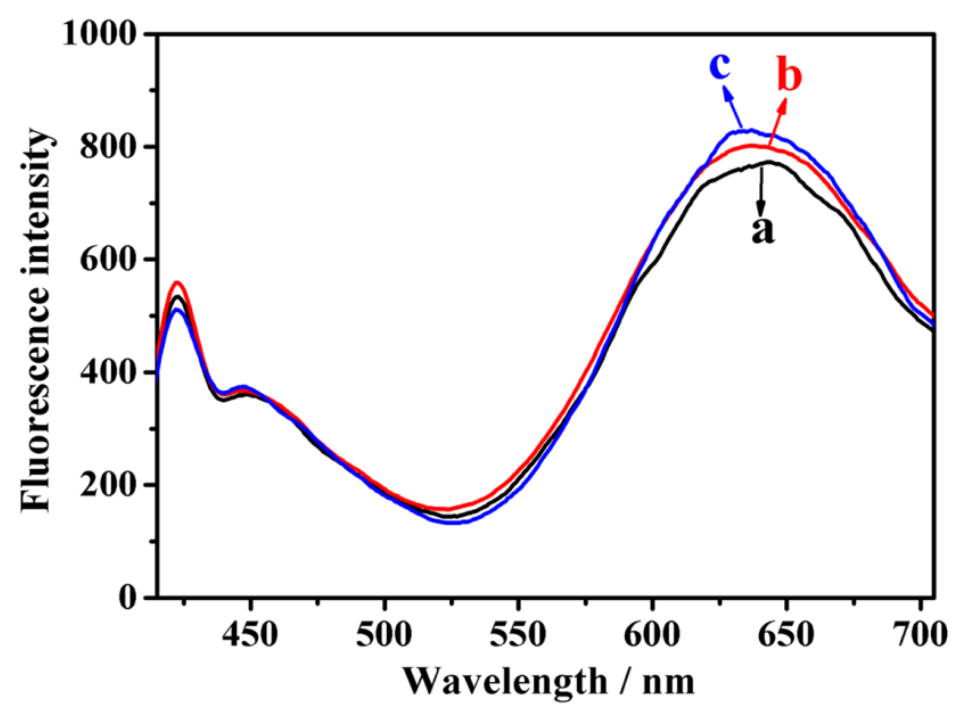

Figure S3. Fluorescence spectra of (a) dLys-AgNCs, (b) dLys-AgNCs + $15 \mathrm{mM} \mathrm{NaF}$, (c) dLys-AgNCs $+1.5 \mathrm{mM}$ thiourea.

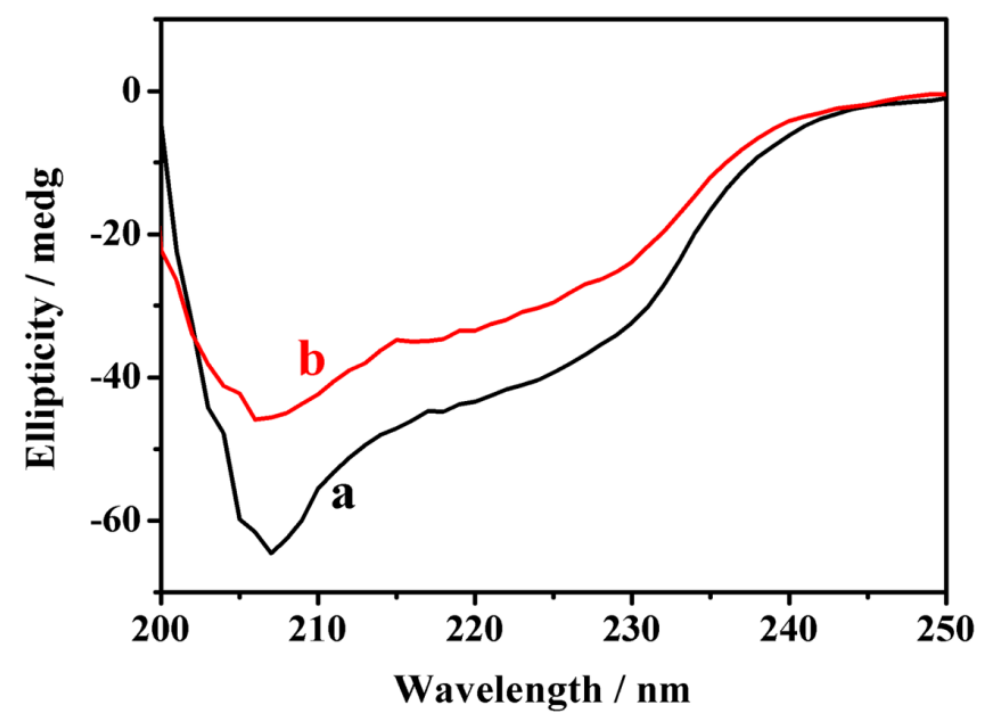

Figure S4. Circular dichroism (CD) spectra of (a) dLys-AgNCs and (b) dLys-AgNCs $+25 \mu \mathrm{M} \mathrm{Fe}^{2+}+25 \mu \mathrm{M} \mathrm{H}_{2} \mathrm{O}_{2}$. 


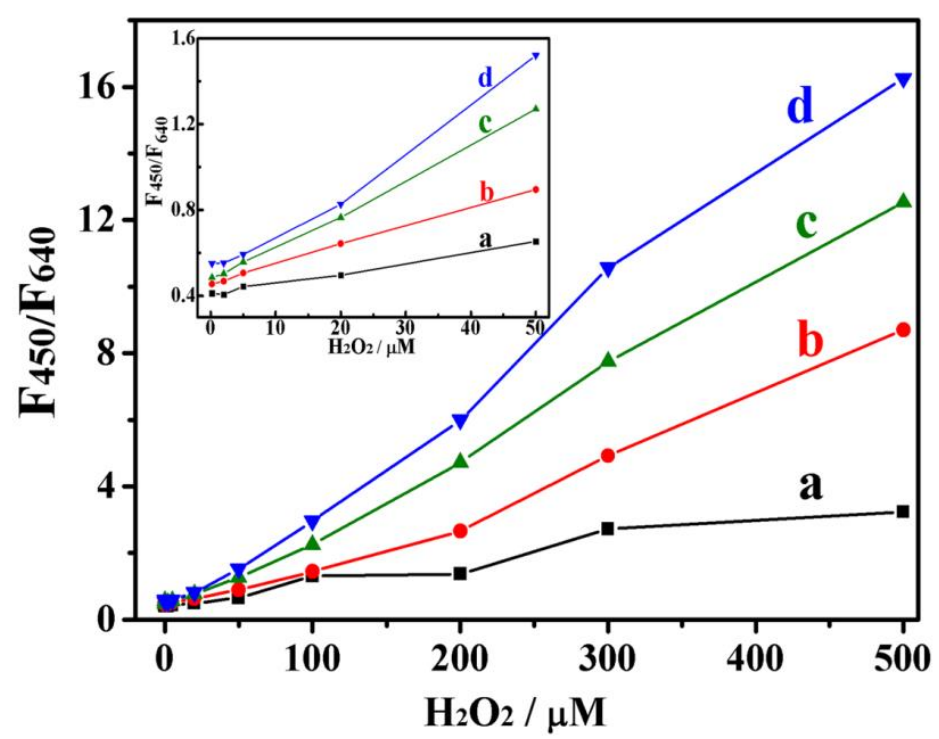

Figure S5. Effect of dLys-AgNCs probe concentrations on the sensing for $\mathrm{H}_{2} \mathrm{O}_{2}$. The prepared dLys-AgNCs were diluted (a) 5-fold, (b)10-fold, (c)15-fold and (d)20-fold, respectively. Inset: amplification in low concentrations range of $\mathrm{H}_{2} \mathrm{O}_{2}(0-50 \mu \mathrm{M})$.

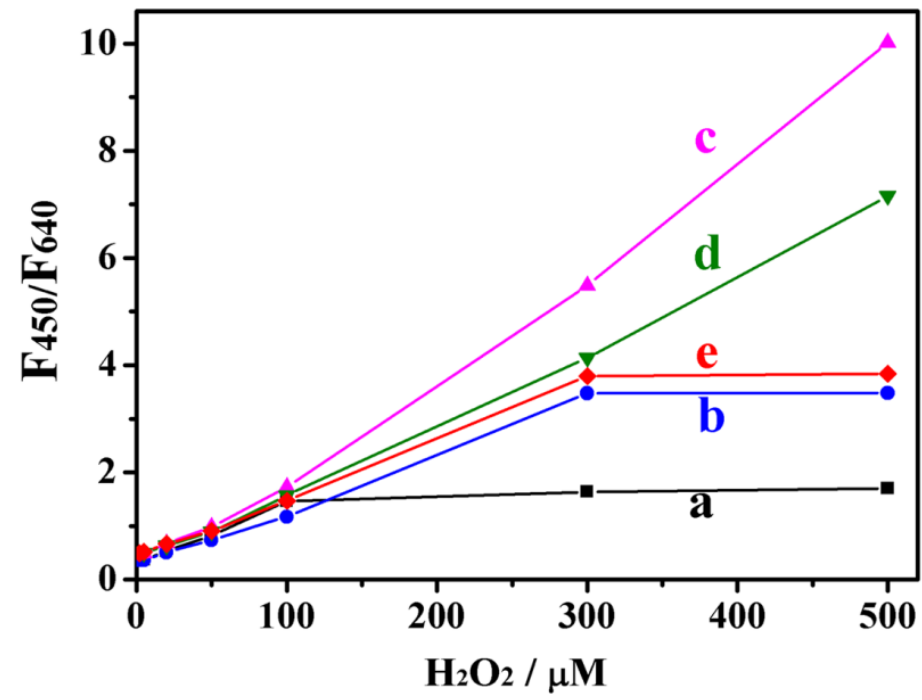

Figure S6. Effect of $\mathrm{Fe}^{2+}$ concentration on the sensing of dLys-AgNCs toward $\mathrm{H}_{2} \mathrm{O}_{2}$. The concentrations of $\mathrm{Fe}^{2+}$ were $(\mathrm{a}-\mathrm{e}) 0.1,0.3,0.5,0.8$ and $1.0 \mathrm{mM}$, respectively. 


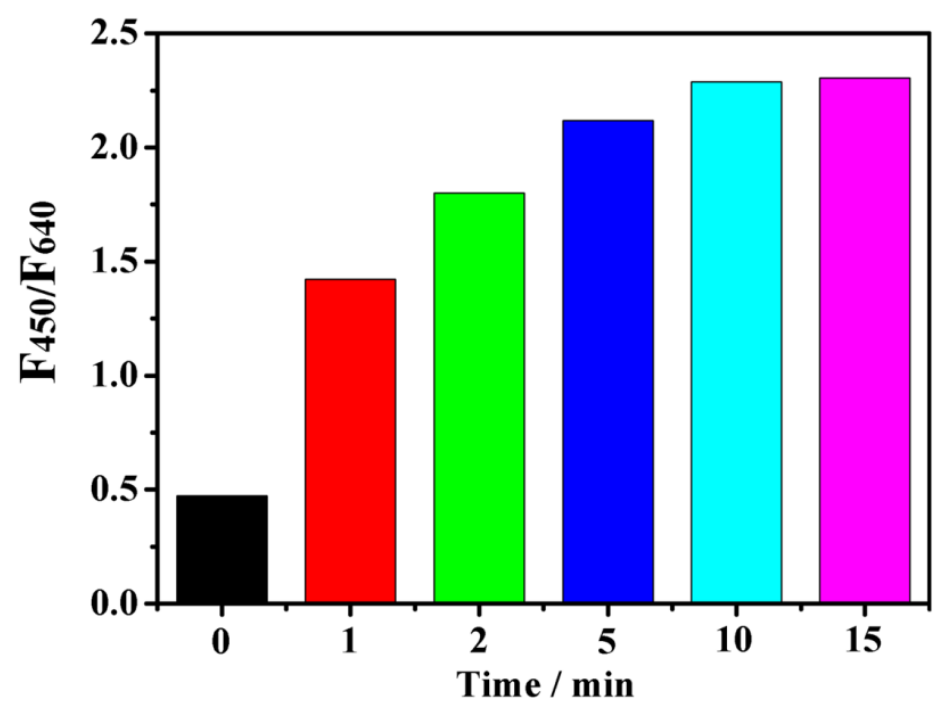

Figure S7. Time-dependent fluorescence sensing of dLys-AgNCs toward $\mathrm{H}_{2} \mathrm{O}_{2}$. The concentration of $\mathrm{H}_{2} \mathrm{O}_{2}$ was $200 \mu \mathrm{M}$.

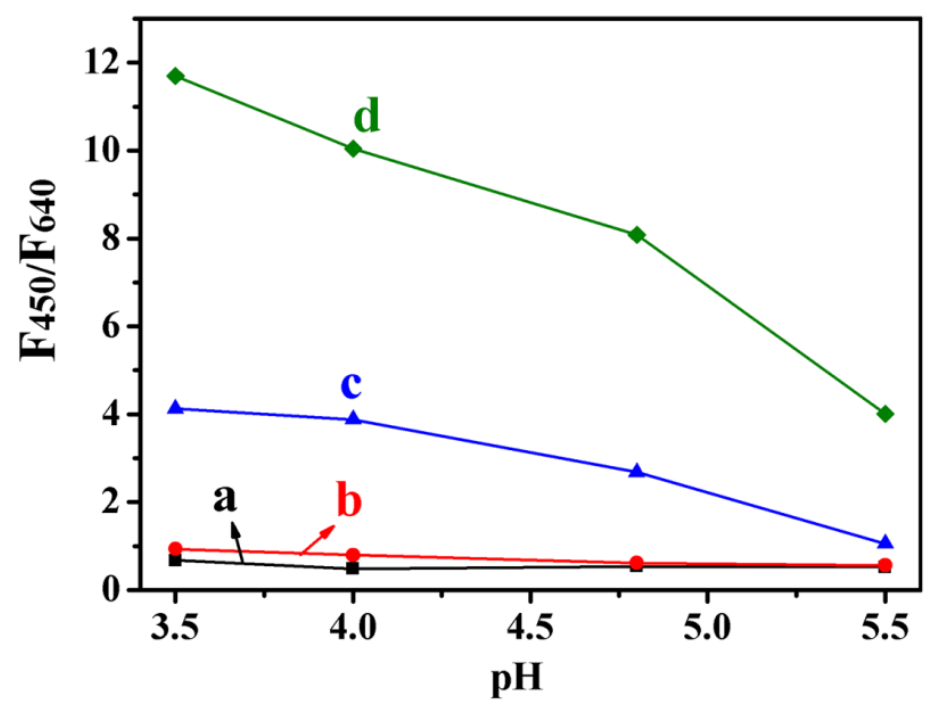

Figure S8. Effect of $\mathrm{pH}(3.5-5.5)$ on the sensing of dLys-AgNCs toward $\mathrm{H}_{2} \mathrm{O}_{2}$ in acetate buffer solution. The concentrations of $\mathrm{H}_{2} \mathrm{O}_{2}$ were $(\mathrm{a}-\mathrm{d}) 0.8,8,80$, and $200 \mu \mathrm{M}$, respectively. 


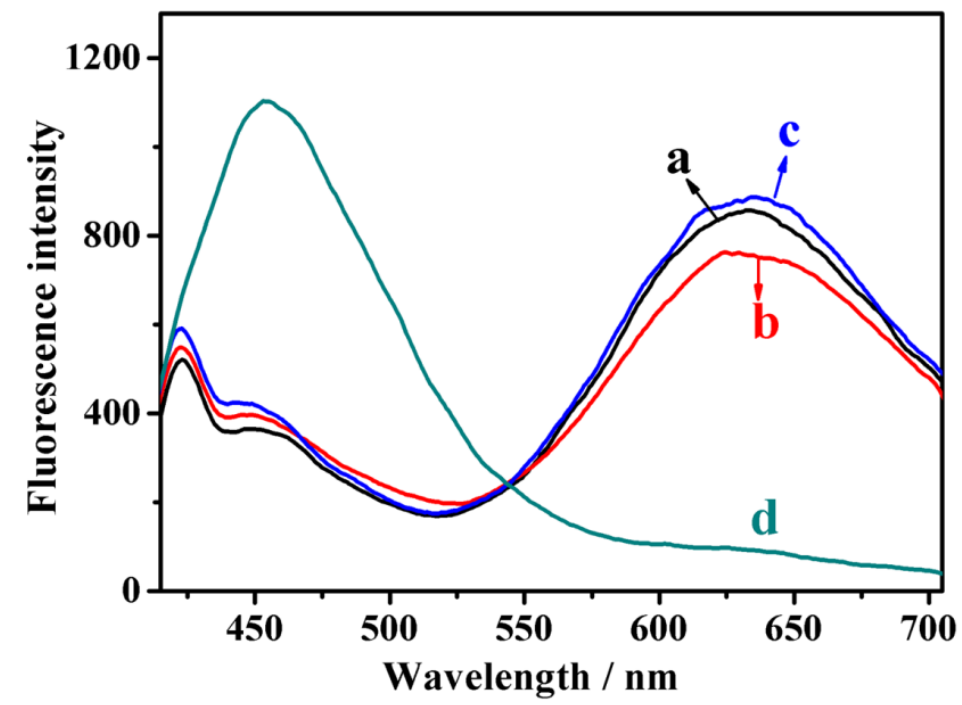

Figure S9. Fluorescence spectra of (a) dLys-AgNCs $+0.5 \mathrm{mM} \mathrm{Fe}{ }^{2+}$, (b) dLys-AgNCs $+0.5 \mathrm{mM} \mathrm{Fe}{ }^{2+}+1 \mathrm{U} / \mathrm{mL}$ GOx, (c) dLys-AgNCs $+0.5 \mathrm{mM} \mathrm{Fe}^{2+}+500 \mu \mathrm{M}$ glucose (d) dLys-AgNCs $+0.5 \mathrm{mM} \mathrm{Fe}{ }^{2+}+1 \mathrm{U} / \mathrm{mL} \mathrm{GOx}+500 \mu \mathrm{M}$ glucose .

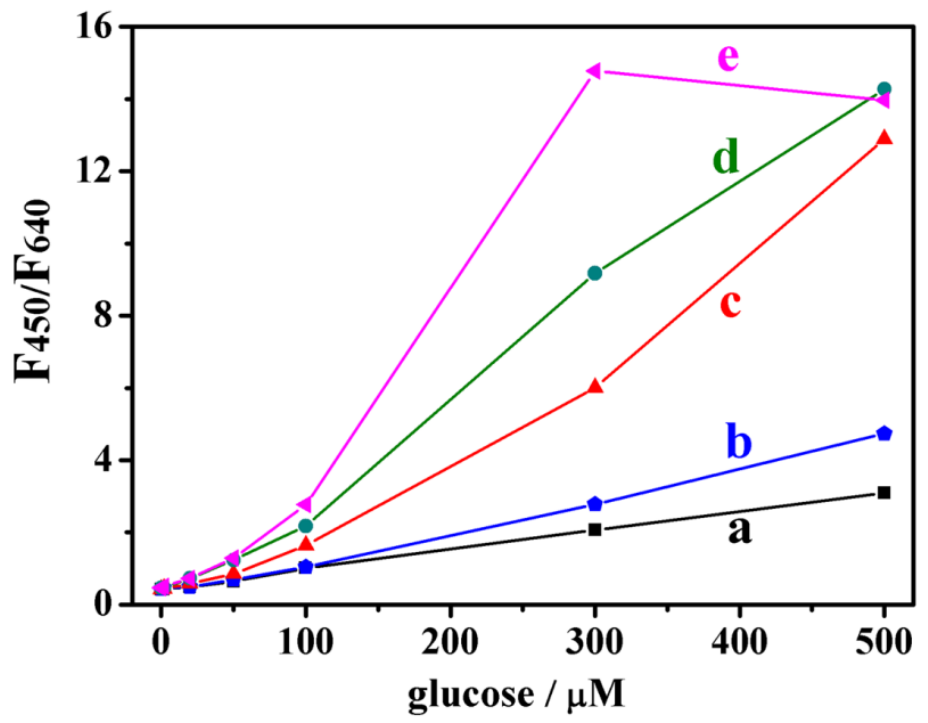

Figure S10. Effect of GOx concentration on the sensing of dLys-AgNCs toward glucose. The concentrations of GOx were $(\mathrm{a}-\mathrm{e}): 0.1,0.2,0.5,1.0$ and $2.0 \mathrm{U} / \mathrm{mL}$, respectively. 


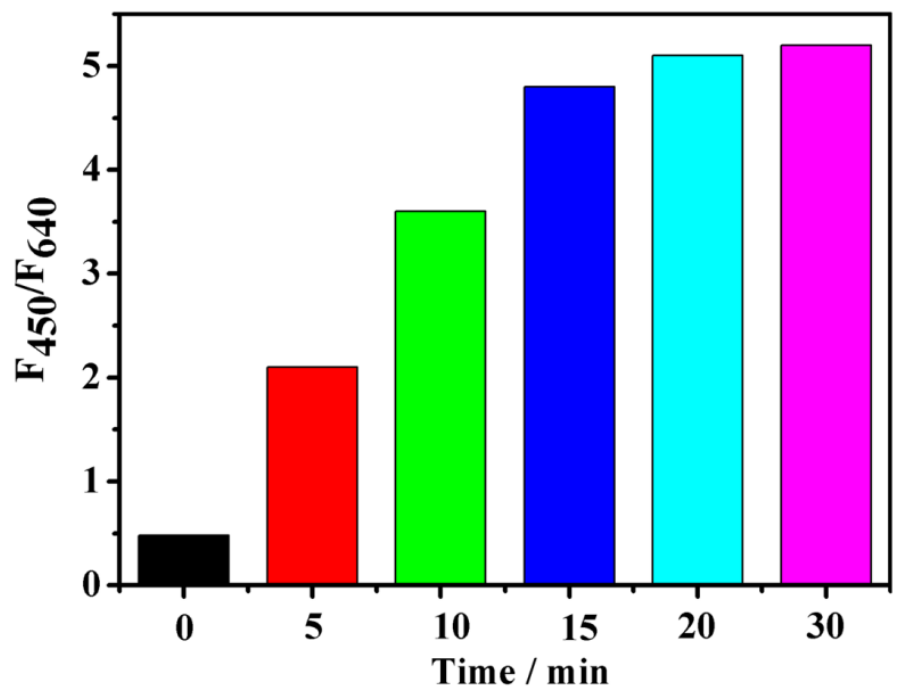

Figure S11. Time-dependent fluorescence sensing of dLys-AgNCs toward glucose. The concentration of glucose was $200 \mu \mathrm{M}$.

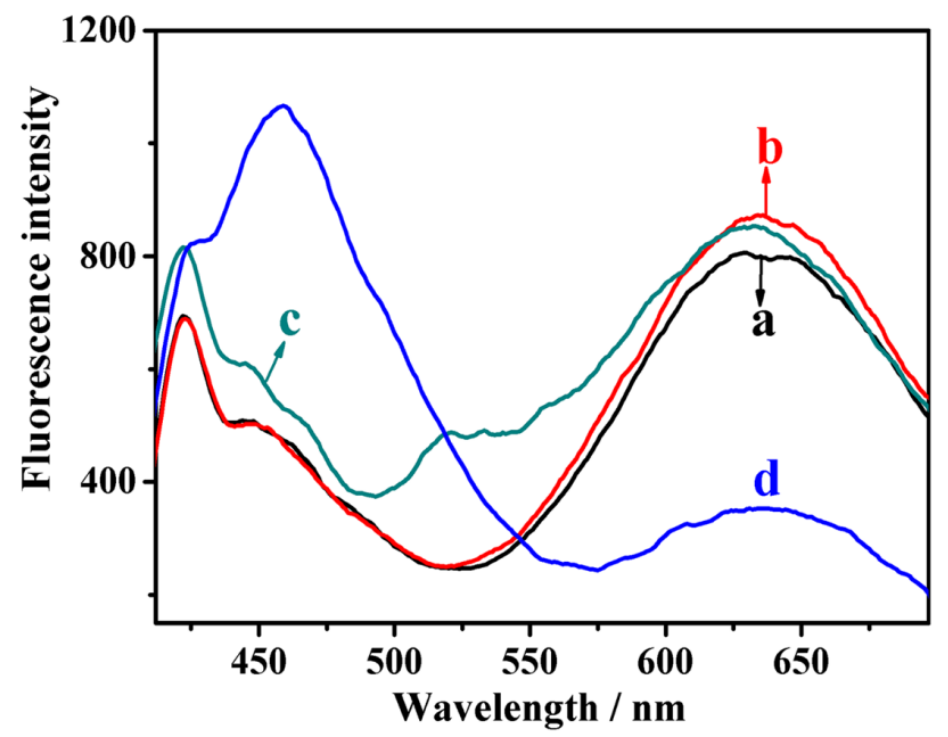

Figure S12. Fluorescence spectra of (a) dLys-AgNCs $+0.5 \mathrm{mM} \mathrm{Fe}^{2+}$, (b) dLys-AgNCs $+0.5 \mathrm{mM} \mathrm{Fe}^{2+}+100 \mu \mathrm{M} \mathrm{ACh},(\mathrm{c}) \mathrm{dLys}-\mathrm{AgNCs}+0.5 \mathrm{mM} \mathrm{Fe}{ }^{2+}+1.0$ $\mathrm{U} / \mathrm{mL} \mathrm{AChE}+0.5 \mathrm{U} / \mathrm{ml} \mathrm{ChOx},(\mathrm{d})$ dLys-AgNCs $+0.5 \mathrm{mM} \mathrm{Fe}{ }^{2+}+1.0 \mathrm{U} / \mathrm{mL} \mathrm{AChE}+$ $0.5 \mathrm{U} / \mathrm{ml} \mathrm{ChOx}+100 \mu \mathrm{M}$ ACh. 
A
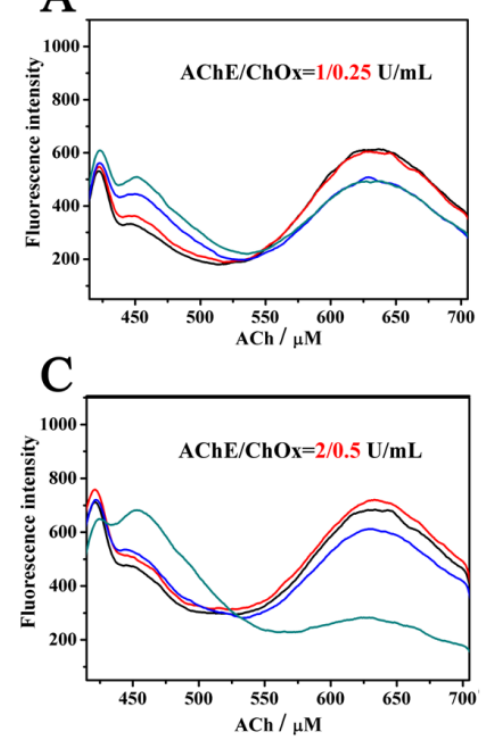

B

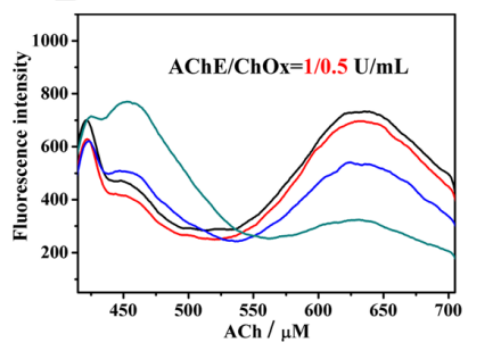

D

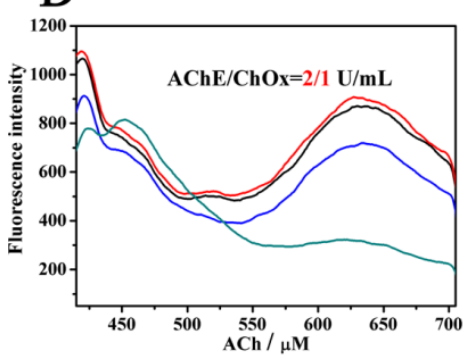

Figure S13. Effect of AChE/ChOx concentrations on the sensing of dLys-AgNCs toward different concentrations of ACh: $0 \mu \mathrm{M}$ (black curve), $2 \mu \mathrm{M}$ (red curve), $20 \mu \mathrm{M}$ (blue curve) and $100 \mu \mathrm{M}$ (green curve). The concentrations of $\mathrm{AChE} / \mathrm{ChOx}$ were (A-D) $1 / 0.25 \mathrm{U} / \mathrm{mL}, 1 / 0.5 \mathrm{U} / \mathrm{mL}, 2 / 0.5 \mathrm{U} / \mathrm{mL}$ and $2 / 1 \mathrm{U} / \mathrm{mL}$.

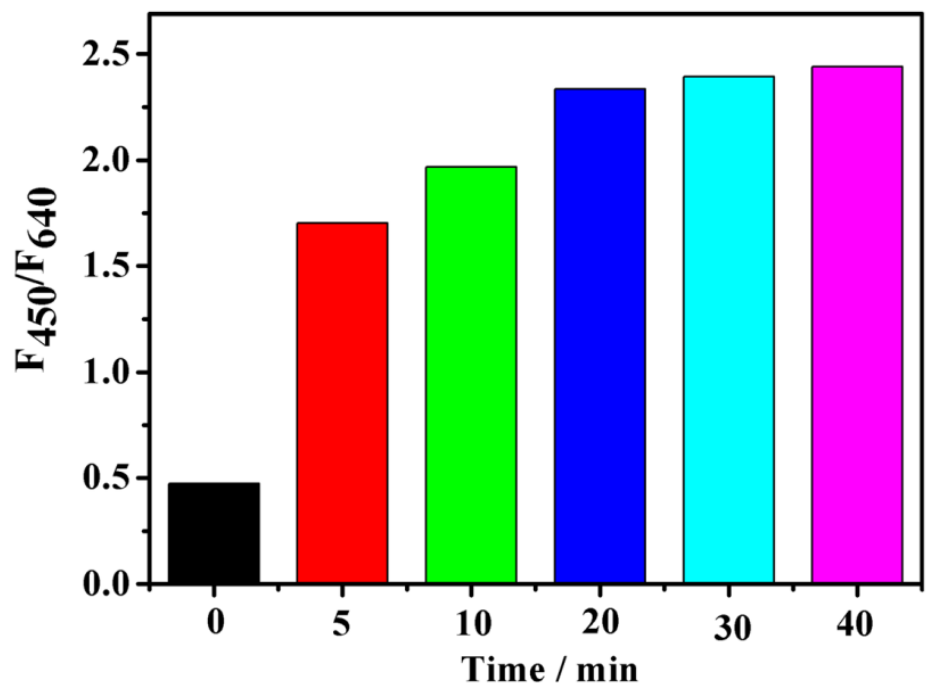

Figure S14. Time-dependent fluorescence sensing of dLys-AgNCs toward ACh. The concentration of ACh was $50 \mu \mathrm{M}$. 


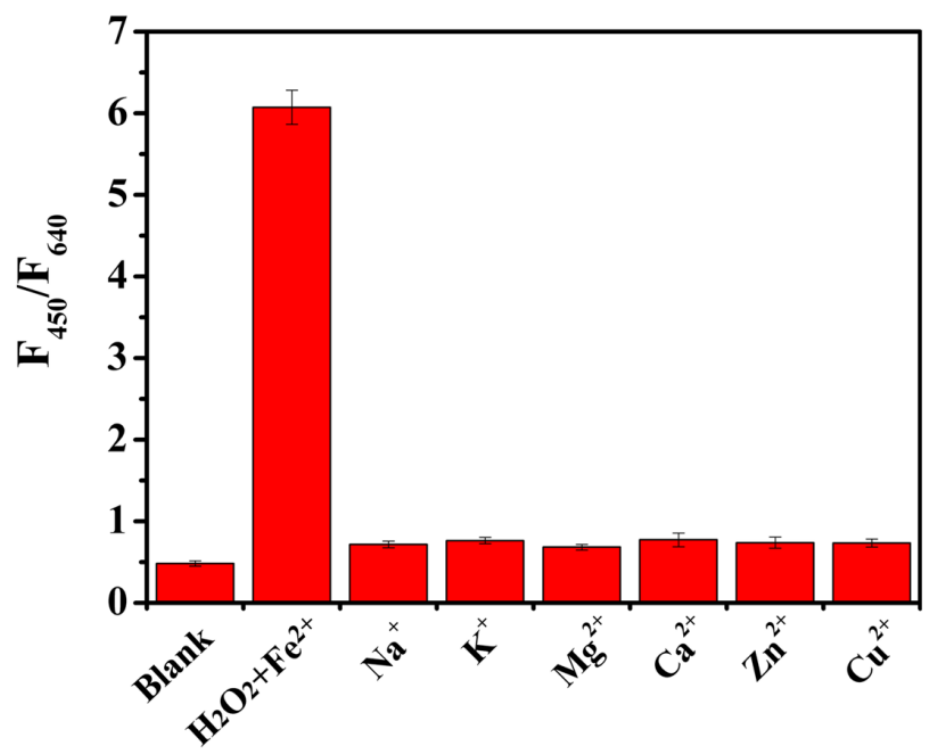

Figure S15. Ratiometric fluorescent response of dLys-AgNCs to Fenton reagents (200 $\mu \mathrm{mol} / \mathrm{L} \mathrm{H}_{2} \mathrm{O}_{2}+0.5 \mathrm{mmol} / \mathrm{L} \mathrm{Fe}^{2+}$ ) and defferent metal ions. The concentrations of metal ions were $100 \mu \mathrm{mol} / \mathrm{L}$. 